九州大学学術情報リポジトリ

Kyushu University Institutional Repository

\title{
Application of Bamboo Vinegar with Process to Evaluate Fungi Resistance of Bamboo Materials
}

Lin, Han Chien

College of Agriculture, National Chiayi University, Chiayi, Taiwan

Ohuchi, Takeshi

Murase, ]Yasuhide

Shiah, Tsang-Chyi

College of Agriculture, National Chiayi University, Chiayi, Taiwan

他

https://doi.org/10.5109/4702

出版情報：九州大学大学院農学研究院紀要. 51 (1)，pp.5-11，2006-02-01. Faculty of Agriculture， Kyushu University

バージョン :

権利関係 : 


\title{
Application of Bamboo Vinegar with Vacuum Process to Evaluate Fungi Resistance of Bamboo Materials
}

\author{
Han Chien LIN ${ }^{1}$, Takeshi OHUCHI ${ }^{2}$, Yasuhide MURASE ${ }^{2}$, Tsang-Chyi SHIAH ${ }^{3 *}$, \\ Shuh-Lin SHIEH ${ }^{4}$, Pei-Chun CHIU ${ }^{4}$, Yu-Mei JUAN ${ }^{4}$ \\ and Shih-Chiang CHENG $^{4}$
}

\author{
Laboratory of Wood Material Technology, Division of Biomaterial Science, Department of \\ Forest and Forest Products Sciences, Faculty of Agriculture, \\ Kyushu University, Fukuoka 812-8581, Japan \\ (Received October 20, 2005 and accepted November 16, 2005)
}

\begin{abstract}
The aim of this study was to evaluate the vinegar obtained from Moso bamboo (Phyllostachys heterocycla), as a fungi resistant agent using the vacuum process, for treating bamboo-based products. The intent was to use this by-product to increase the value-added part of the products, and at the same time provide a substitute for the current use of fungicides, in order to reduce environmental pollution. The specimens used were Moso bamboo that had been processed with either the carbonizing or the steaming process. Exposure to fungi from the air for $30 \mathrm{~min}$ and four strains of experimental fungi were used, including Aspergillus niger, Mucor sp., Penicillum sp., and Trichoderma viride. From the results obtained, it was evident that the fungal resistance of the molds on the bamboo surface increased with the increased uptake of the bamboo vinegar, as measured by time period of vacuum and impregnation, and the $\mathrm{C} / \mathrm{N}$ ratio of fungi inoculated bamboo powder was increased as well. The FTIR analysis showed that when the bamboos were treated with the vacuum process at $60 \mathrm{~min}$ of vacuum period and $240 \mathrm{~min}$ of impregnation time, no functional groups of the fungal chemical compounds, at $1654 \mathrm{~cm}^{-1}(\mathrm{C}=\mathrm{O})$ and $1552 \mathrm{~cm}^{-1}(\mathrm{~N}-\mathrm{H})$, were found after 70 days. From this it was concluded that bamboo vinegar is useful to restrain the molds and that it can decrease microbiological deterioration of bamboo materials.
\end{abstract}

\section{INTRODUCTION}

According to the annual statistics of the agricultural reports in Taiwan (2003), from 1994 to 2003, the average number of various bamboos that were harvested amounted to about 1,422,316 pieces every year. The main types of bamboo used included Makino bamboo (Phyllostachys makinoi Hayata) 1,089,959 pieces, Moso bamboo (Phyllostachys heterocycla Milf) 20,773 pieces, Ma bamboo (Dendrocalamus latiflorus Munro) 13,168 pieces, and others. In other words, three main types of bamboos make up about two-third of all bamboo materials used, indicating that bamboo is one of the economic green resources in Taiwan. Among these bamboos, Moso bamboo has been mainly used as a material for the making of furniture, handicrafts, and athletic/leisure goods, because it can grow over $20 \mathrm{~m}$ tall and $60-150 \mathrm{~mm}$ in diameter in one growing season (Wang and Shen, 1987a).

Bamboo-based products are susceptible to mold problems and are readily attacked by worms, which causes major financial losses, especially for valuable bamboo-made handicrafts. This problem is due to the

1,3 Department of Forest Products Science, College of Agriculture, National Chiayi University, Chiayi, Taiwan, ROC.

2 Laboratory of Wood Material Technology, Division of Biomaterial Science, Department of Forest and Forest Products Sciences, Faculty of Agriculture, Kyushu University, Japan.

4 Graduate Student, Department of Forest Products Science, College of Agriculture, National Chiayi University, Chiayi, Taiwan, ROC.

* Corresponding author (E-mail: tc.shiah@msa.hinet.net) fact that bamboo contains lots of nutritive substances such as components of starch (Wang et al., 1987b; Liese, 1980). This susceptibility is an important issue with a heavy influence on the value and durability of bamboo-based products. The mold problem has been a nightmare since time immemorial for people working in the bamboo craft industry. A traditional method for keeping bamboo materials fungi free is to keep them in a nominally humid condition (Council for Cultural Affairs, 2002), but these requirements are too expensive for general use. Another method is to process the bamboo with some chemical fungicide or artificial preservatives to prevent this problem from occurring (Shieh, 1976; Sulthoni, 1988; Council for Cultural Affairs, 2002), however, this is of limited value because this can too easily pollute the environment.

Bamboo vinegar, a by-product from bamboo charcoals, contains over 200 kinds of organic compounds, such as organic acids, phenolic compounds, alkone compounds, alcohol compounds, aldehyde compounds, and others (Uchimura et al., 2000; Ikimoto and Ikeshima, 2000; Nomura, 2004). It is effective to improve soil, promote crop or prevent worm growth, as well as to reduce agricultural chemical, compost odor, and sterilization (Ikimoto and Ikeshima, 2000; Lin, 1995). Recently, bamboo vinegar has also been developed for use in skincare products, against allergic reactions, as a health drink, as a virus/fungi resistant product, and it even can be used to cure diabetes mellitus according to social and medical reports (Mizuki, 2004; Hageta, 2004; Kobahasi, 2004; Yoshie, 2004). As a result, the commercial development of bamboo vinegar is being increased in Taiwan, where it being valued highly for its various effective 
uses. The aim of this study was to evaluate the vinegar obtained from Moso bamboo, as a fungi resistant agent using the vacuum process, for treating bamboo-based products such as furniture, handicrafts and others. The intent was to use this by-product to add increased value to the products, and at the same time provide a substitute for the current use of fungicides, in order to reduce environmental pollution.

\section{MATERIALS AND METHODS}

\section{Specimen preparations \\ Bamboo}

Moso bamboo (Phyllostachys heterocycla Milf) was provided by $\mathrm{Pu}$ Yuan Co. Ltd., Nantour, Taiwan. Two types of specimens were used. One was pre-processed by means of the steaming process, which means boiling it in water for $3 \mathrm{~h}$ and then air-drying it. The other type of specimen was pre-processed using the carbonizing process; the processing conditions for which were: a temperature of 120 to $130^{\circ} \mathrm{C}$ for $1.5 \mathrm{~h}$. In general, both these process methods are being used regularly for bamboo materials by bamboo working companies in Taiwan. The purpose for the steaming process is to remove the starch from the bamboo, and the carbonizing process is to reduce the internal stress or the decay in the bamboo. Two types of bamboo specimens were air-dried and the specimens, measuring $25 \mathrm{~mm} \times 25 \mathrm{~mm} \times 3 \mathrm{~mm}(\mathrm{~T})$ were prepared. All specimens were conditioned to equilibrium at $20^{\circ} \mathrm{C}$ with $65 \%$ relative humidity $(\mathrm{RH})$ for about four weeks. The average moisture content of all specimens was 8.9 to $9.7 \%$, and the density at this moisture content was $0.74(0.01) \mathrm{g} / \mathrm{cm}^{3}$ for the steamed specimens, and $0.67(0.01) \mathrm{g} / \mathrm{cm}^{3}$ for the carbonized specimens.

\section{Bamboo vinegar}

Bamboo vinegar was provided by $\mathrm{Pu}$ Yuan Co. Ltd., Nantou, Taiwan which was manufactured from Moso bamboo charcoal. The vinegar is light yellow in color after first being treated with purification, including distillation and resting for over 2 years. Its solid content was about $0.0193 \%$, specific gravity was 1.090 , and $\mathrm{pH}$ value was 2.5 .

\section{Nutrient media}

Potato-dextrose agar (PDA) was used as a nutrient media to obtain the fungi in petri dishes (TAPPI, 1993) for this experimental use. Water agar (WA) was used as a nutrient media to maintain/grow the fungi to be used in the test with either of the specimen in petri dishes (TAPPI, 1993). PDA and WA were obtained from Merck Co. PDA was prepared using $39 \mathrm{~g}$ with $1000 \mathrm{ml}$ of tap water, and WA was prepared using $8 \mathrm{~g}$ of Agar-Agar with $400 \mathrm{ml}$ of tap water. Both preparations were then mixed thoroughly prior to sterilization.

\section{Inoculation}

Fungi were produced in the laboratory by placing Moso bamboo specimens into a humidified cabinet (LH-112, Tabai Espec Corp.) at $20^{\circ} \mathrm{C}$ with $95 \% \mathrm{RH}$ for at least 2 weeks. A sterile inoculating needle was used to take fungi samples from the bamboo surface and put them into the petri dishes. After incubating onto PDA, the fungi were then fully developed in the dishes using an incubator (Model PG-201, Firstek Scientific) at a temperature of $25^{\circ} \mathrm{C}$ for over 1 week. Each fungus was isolated and purified before they it was placed into the sterile containers. Four main strains of fungi were obtained in this pre-experimental exercise, and they are: Aspergillus niger, Mucor sp., Penicillum sp., and Trichoderma viride. In general, those fungi have been presented before on microbiological attack of the surface of wood or paper-based materials in Taiwan (Shieh, 1976; Wang et al, 1987b; Council for Cultural Affairs, 2002; Shiah and Chang, 2002). In addition, Chang et al. (1983) reported that the fungi always come from the air, which depends upon the frequency and quantity of the air borne spores. The fungi from air borne spores were therefore one of the test conditions in this study. In other words, the bamboo specimens were exposed to the air in an indoor atmosphere for a period of $30 \mathrm{~min}$.

\section{Experimental methods}

Vacuum process

The Moso bamboo specimens for both types of specimens, steamed and carbonized, were treated with bamboo vinegar, using a vacuum apparatus (including a desiccator, a pressure gauge, a separator funnel, and a vacuum pump). The volume was kept under a constant pressure of over $600 \mathrm{~mm} / \mathrm{Hg}$, and then impregnated with the bamboo vinegar. There were three different process conditions. Vacuum process A consisted of $10 \mathrm{~min}$ of vacuum and $60 \mathrm{~min}$ of impregnation, vacuum process $B$ was $30 \mathrm{~min}$ of vacuum and $120 \mathrm{~min}$ of impregnation time, and vacuum process $C$ was $60 \mathrm{~min}$ of vacuum period and 240 min of impregnation time. Subsequently, these specimens were individually removed to a drainage pad, and tipped on end to allow for drainage. The specimens were briefly wiped with a paper towel to remove the surface vinegar and then weighed to determine the amount of absorption. Afterwards, the specimens were air-dried for $24 \mathrm{~h}$, and then placed into a convection oven at $30^{\circ} \mathrm{C}$ for over $30 \mathrm{~min}$ after which they were cooled and stored in plastic bags for at least 3 days to allow the FR fixation reaction to proceed. They were then reconditioned at $20^{\circ} \mathrm{C}$ with $65 \% \mathrm{RH}$ for 2 weeks. Six replicates of specimen were prepared for each type of fungi, for each of the vacuum processes.

\section{Fungi inoculation and fungal resistance}

The hands of the operator as well as the necessary equipment were sterilized by first spraying with $70 \%$ alcohol. The inoculating needle and the mouths of the sterile containers were sterilized using an alcohol lamp. After the WA on the petri dishes had solidified, the counting of the fungi colony was carried out using a colony counter (4BH-24, High Ten Co.). Each fungus was then inoculated by distributing 3 drops (about $3 \mathrm{ml}$ ), onto the surface of the processed specimen in a petri dish, and then incubating the petri dishes containing the inoculated test-specimens for a time period at a temperature of $25^{\circ} \mathrm{C}$ atmosphere till the growth of each tested fungus was seen. The fungal resistance 
experiments were determined by visual examination. Total absorption

The total absorption was calculated using the following equation:

$$
\text { Absorption (\%) }=\mathrm{Wa}-\mathrm{Wb} / \mathrm{Wa} \times 100
$$

where $\mathrm{Wa}$ is the specimens weight after any of the vacuum processes, and $\mathrm{Wb}$ is the weight of the specimens before any these processes.

Surface texture

Using a surface texture-measuring instrument (Semitsu, Tokyo), the surface texture measuring of the specimens was carried out for each type of processed bamboo, including the controls and the specimens after each process. This measurement involved the degree of texture of both the vertical and horizontal fiber directions at the surface of the specimen. The average degree of the surface texture on the centerline of the specimen ( $\mathrm{Ra})$, the degree of the texture at the highest point on the surface of the specimen (Rmax), and the average degree of the texture for ten points on the surface of the specimen $(\mathrm{Rz})$ were measured.

\section{Color change}

The processed specimens for both the steaming and the carbonizing processes were measured using a colorimeter (Nippon Denshoku NR-3000) at 3 randomly selected spots. In the CIE $1976 \mathrm{~L}^{*} \mathrm{a}^{*} \mathrm{~b}^{*}$ color system employed in this study, color is considered to consist of three major dimensions: hue, chroma, and lightness. $\mathrm{L}^{*}$ is the lightness or brightness variable and is generally the most important aspect of wood color changes to a viewer's eye, while $a^{*}$ and $b^{*}$ represent the chromaticity (hue and chroma) coordinates. The color difference ( $\Delta$ $\mathrm{E}^{*}$ ) was evaluated as well.

Statistics analysis

Results of surface texture, color change, and amount of absorption were statistically analyzed based on Duncan's multiple range tests at 5\% significant level analysis, using the Statistical Package for Social Science (SPSS) software.

\section{$\mathrm{C} / \mathrm{N}$ ratio measurement}

The samples, about 2-4 mg oven dried each, with various fungi that were individually inoculated on two types of specimens with various processes were analyzed after 70 days using an Elemental Vario CHNS/O analyzer (EA, Germany). The result of the $\mathrm{C}$ and $\mathrm{N}$ elements was obtained and then the $\mathrm{C} / \mathrm{N}$ ratio was calculated.

\section{FTIR analysis}

When the fungi was inoculated for 70 days, the specimens of each of the various processes were analyzed using the reflectance mode of Fourier Transform Infrared Spectroscopy (FTIR, Perkin Elmer Spectrum RX 1) at a resolution of $4 \mathrm{~cm}^{-1}$. Thirty-two scans were co-added for each spectrum. Infrared transmittance spectra were measured over the range of $650-4000 \mathrm{~cm}^{-1}$. The peak assignments were performed using the Win FIRST software program.

\section{RESULTS AND DISCUSSION}

\section{Basic properties}

To examine the influence of the vacuum process on the absorption of bamboo vinegar, three types of processes were carried out. The total absorptions for both the steamed and the carbonized bamboo specimens are shown in Table 1. The results show that the amounts of absorption by both types of specimens were as follows: vacuum process $\mathrm{A}$ was about 43.08 to $44.88 \%$, followed by 49.32 to $50.95 \%$ for vacuum process $\mathrm{B}$, followed by 57.75 to $68.39 \%$ for vacuum process $\mathrm{C}$. Based on the difference in process, the difference of absorption varied significantly (5\%) by Duncan's multiple range tests, expressed by different alphabets, even for those specimens that had undergone a different pre-process. This suggests that the absorption of the specimens increases with the increase in both the duration of the vacuum and the amount of impregnation.

Table 1. Absorption of bamboo vinegar for two types of preprocess Moso bamboo specimens with various processes.

\begin{tabular}{ccc}
\hline \multirow{2}{*}{ Treatment } & \multicolumn{2}{c}{ Moso bamboo } \\
\cline { 2 - 3 } & Steamed specimens & Carbonized specimens \\
\hline $\mathrm{A}^{1)}$ & $44.88(4.17)^{\mathrm{a}}{ }^{4)}$ & $43.08(4.26)^{\mathrm{a}}$ \\
$\mathrm{B}^{2)}$ & $50.95(3.31)^{\mathrm{b}}$ & $49.32(5.08)^{\mathrm{b}}$ \\
$\mathrm{C}^{3)}$ & $68.39(7.52)^{\mathrm{c}}$ & $57.75(2.97)^{\mathrm{c}}$ \\
\hline
\end{tabular}

1) Vacuum process $\mathrm{A}$ ( $10 \mathrm{~min}$ of vacuum period and $60 \mathrm{~min}$ of impregnation time).

2) Vacuum process $B$ ( $30 \mathrm{~min}$ of vacuum period and $120 \mathrm{~min}$ of impregnation time).

3) Vacuum process C (60 min of vacuum period and $240 \mathrm{~min}$ of impregnation time).

4) Mean (standard deviation) separation within columns by Duncan's multiple range tests at 5\% significant level.

To evaluate the change of surface texture of the two types of Moso bamboo after each process, the degree of texture to both the horizontal and the vertical fibers directions were investigated. The results are shown in Table 2. When comparing the surface texture of each type of specimen on either fiber direction, the Duncan's multiple range tests varied significantly. In addition, Duncan's statistics analysis indicated that $\mathrm{Ra}$ was unchanged on the horizontal and vertical fiber direction for the carbonized specimens after the various processes, as expressed by the same alphabet. In general, a porous material can contribute to swelling/absorption of the constituents and change the direction of the micro-fibers after soaking with a water type of solution (Takeuchi, 2000). It is recommended that after processing, in order to obtain a better surface on the final product (e. g. handicraft), of bamboo-based materials, some kind of water-based solution, such as bamboo vinegar, is advisable to be worked in the bamboo surface.

Generally speaking, color changes are the most important aspect of wood-based materials to a consumer, and $\mathrm{L}^{*} \mathrm{a}^{*} \mathrm{~b}^{*}$ are also the most frequently mea- 
Table 2. Surface texture for two types of pre-process Moso bamboo specimens with various processes.

\begin{tabular}{|c|c|c|c|c|c|c|c|}
\hline \multirow{2}{*}{$\begin{array}{c}\text { Moso } \\
\text { bamboo }\end{array}$} & \multirow{2}{*}{ Treatmen } & \multicolumn{3}{|c|}{ Texture degree to horizontal fiber direction } & \multicolumn{3}{|c|}{ Texture degree to vertical fiber direction } \\
\hline & & $\mathrm{Ra}^{4)}$ & $\operatorname{Rmax}^{4)}$ & $\mathrm{Rz}^{4)}$ & $\mathrm{Ra}$ & $\operatorname{Rmax}$ & $\mathrm{Rz}$ \\
\hline \multirow{4}{*}{$\begin{array}{c}\text { Steamed } \\
\text { specimens }\end{array}$} & Control & $2.08(0.69)^{\text {a 5) }}$ & $18.99(05.21)^{\mathrm{a}}$ & $14.16(04.30)^{\mathrm{a}}$ & $4.03(1.40)^{\mathrm{a}}$ & $38.82(17.02)^{\mathrm{a}}$ & $25.71(08.92)^{\mathrm{a}}$ \\
\hline & $A^{1)}$ & $2.85(1.34)^{b}$ & $35.72(13.78)^{b}$ & $23.41(09.06)^{b}$ & $5.21(1.17)^{\mathrm{b}}$ & $74.84(22.97)^{b}$ & $46.77(12.51)^{b}$ \\
\hline & $\mathrm{B}^{2)}$ & $2.28(0.79)^{\mathrm{b}}$ & $39.45(10.13)^{b}$ & $22.73(07.23)^{b}$ & $4.11(0.79)^{a}$ & $64.75(14.06)^{b}$ & $43.31(06.59)^{b}$ \\
\hline & $\mathrm{C}^{3)}$ & $3.15(1.48)^{\mathrm{bc}}$ & $47.14(19.40)^{\mathrm{c}}$ & $29.81(15.06)^{b}$ & $4.81(0.89)^{\text {at }}$ & $73.30(21.82)^{b}$ & $44.63(08.82)^{\circ}$ \\
\hline \multirow{4}{*}{$\begin{array}{l}\text { Carbonized } \\
\text { specimens }\end{array}$} & Control & $1.96(0.77)^{\mathrm{a}}$ & $17.54(06.06)^{a}$ & $11.63(04.27)^{\mathrm{a}}$ & $4.99(0.74)^{\mathrm{a}}$ & $50.97(07.24)^{a}$ & $33.07(05.48)^{\circ}$ \\
\hline & $A^{1)}$ & $2.70(1.17)^{\mathrm{a}}$ & $37.69(14.99)^{b}$ & $23.80(10.17)^{b}$ & $5.16(0.96)^{a}$ & $81.77(15.94)^{b}$ & $48.31(08.15)^{\circ}$ \\
\hline & $\mathrm{B}^{23}$ & $2.92(1.71)^{\mathrm{a}}$ & $38.15(21.55)^{b}$ & $24.84(13.00)^{b}$ & $5.00(1.44)^{\mathrm{a}}$ & $73.12(20.52)^{b}$ & $43.32(12.39)^{\circ}$ \\
\hline & $\mathrm{C}^{3)}$ & $2.82(1.96)^{a}$ & $31.76(21.38)^{b}$ & $22.72(17.01)^{b}$ & $5.61(2.42)^{\mathrm{a}}$ & $66.15(22.79)^{b}$ & $43.55(11.58)$ \\
\hline
\end{tabular}

1).2),3) and 5) The notes are the same as Table 1.

4) Ra: The average degree of the surface texture on the centerline of the specimen. Rmax: The degree of the texture at the highest point on the surface of the specimen. Rz: The average degree of the texture for ten points on the surface of the specimen.

Table 3. Color differences for two types of pre-process Moso bamboo specimens with various processes.

\begin{tabular}{|c|c|c|c|c|c|c|c|c|}
\hline Moso bamboo & Treatment & $L^{* 4)}$ & $a^{* 4)}$ & $\mathrm{b}^{* 4)}$ & $\Delta \mathrm{L}^{* 6)}$ & $\Delta \mathrm{a}^{* 6)}$ & $\Delta \mathrm{b}^{* 6)}$ & $\Delta \mathrm{E}^{* 6)}$ \\
\hline \multirow{4}{*}{$\begin{array}{c}\text { Steamed } \\
\text { specimens }\end{array}$} & Control & $79.91(1.87)$ & $3.85(1.01)$ & $27.90(0.90)$ & - & - & - & - \\
\hline & $A^{1)}$ & $77.99(1.50)$ & $4.45(0.69)$ & 29.37 (1.68) & $11.55(0.09)$ & $-3.64(0.03)$ & $4.01(0.05)$ & $12.80(0.12)^{a 5)}$ \\
\hline & $\mathrm{B}^{2)}$ & $77.03(0.67)$ & $4.98(0.37)$ & $30.74(0.76)$ & $10.59(0.05)$ & $-3.11(0.04)$ & $5.38(0.09)$ & $12.30(0.09)^{\mathrm{a}}$ \\
\hline & $\mathrm{C}^{3)}$ & $73.60(5.38)$ & $5.67(1.80)$ & $26.05(0.21)$ & $7.16(0.02)$ & $-2.42(0.02)$ & $0.69(0.01)$ & $7.59(0.05)^{b}$ \\
\hline \multirow{4}{*}{$\begin{array}{l}\text { Carbonized } \\
\text { specimens }\end{array}$} & Control & $66.44(2.18)$ & $8.09(0.66)$ & $25.36(0.90)$ & - & - & - & - \\
\hline & $A^{1)}$ & $65.56(1.24)$ & $7.92(0.49)$ & $25.56(0.91)$ & $-0.88(0.06)$ & $-0.17(0.00)$ & $0.20(0.01)$ & $0.91(0.02)^{a}$ \\
\hline & $\mathrm{B}^{2)}$ & $66.36(1.25)$ & $8.15(0.51)$ & $25.94(0.58)$ & $-0.08(0.00)$ & $0.06(0.01)$ & $0.58(0.02)$ & $0.59(0.02)^{a}$ \\
\hline & $\mathrm{C}^{3)}$ & $64.31(1.80)$ & $8.46(0.42)$ & $25.58(1.95)$ & $-2.13(0.01)$ & $0.37(0.03)$ & $0.22(0.04)$ & $2.17(0.05)^{a}$ \\
\hline
\end{tabular}

1),2),3) and 5) The notes are the same as Table 1.

4) Color values: $\mathrm{L}^{*}: 0$ to 50 Dark direction, 51 to 100 Light direction; $\mathrm{a}^{*}$ : 0 to +60 Red direction, 0 to $-60 \mathrm{Green}$ direction; $\mathrm{b}^{*}$ : 0 to + 60 Yellow direction, 0 to -60 Blue direction.

6) $\Delta \mathrm{L}^{*}=\mathrm{L}$ control $*-\mathrm{L} i ; \Delta \mathrm{a}^{*}=\mathrm{a}$ contro ${ }^{*}-\mathrm{a} i ; \Delta \mathrm{b}^{*}=\mathrm{b}-{ }^{*}-\mathrm{b} i$; where $i=\mathrm{A}, \mathrm{B}$ or $\mathrm{C}$ (Vacuum process: the duration of the vacuum and the amount of impregnation); $\Delta \mathrm{E}^{*}=\left(\Delta \mathrm{L}^{* 2}+\Delta \mathrm{a}^{* 2}+\Delta \mathrm{b}^{*^{2}}\right)^{1 / 2}$ : Color difference.

sured parameters (Okano et al., 1995). Results of colorimetric measurements of two types of bamboo specimens, based on the CIE L* $a^{*} b^{*}$ system, are presented in Table 3. The $\mathrm{a}^{*}$ for steamed bamboo specimens showed a comparatively significant increase based on the increase in processing time, while $\mathrm{L}^{*}$ and $\mathrm{b}^{*}$ changed little, while the changes for $\mathrm{L}^{*} \mathrm{a}^{*} \mathrm{~b}^{*}$ in carbonized bamboo specimens was insignificant. This is due to the types of experimental materials used: the carbonized bamboo was a deeply colored material, and was processed with Moso bamboo vinegar, the color of which is pale yellow. The surface color of the carbonized bamboo became a bit deeper due to various vacuum processes, the results of the difference in brightness ( $\Delta$ $\left.\mathrm{L}^{*}\right)$, red $\left(\Delta \mathrm{a}^{*}\right)$, and yellow $\left(\Delta \mathrm{b}^{*}\right)$ are also shown in Table 3. According to the change of process, only the color difference $\left(\Delta \mathrm{E}^{*}\right)$ for the steamed specimens at vacuum process $\mathrm{C}$, was significant $(5 \%)$ by Duncan's multiple range test. It must be noted that the steamed specimens were treated with the vacuum process at 60 min of vacuum period and $240 \mathrm{~min}$ of impregnation time, which could cause the surface color effect.

\section{Effect of vacuum process on fungi resistance}

The results of the steamed specimens treated with vacuum processes $A, B$, and $C$, respectively, after being inoculated by various fungi on WA at $25^{\circ} \mathrm{C}$ incubator for 70 days are shown in Fig. 1. The fungi resistance for the control specimens, without bamboo vinegar, was ineffective ( $100 \%$ of fungal colony growth), but it was enable the specimen to obtain the fungi resistance after each vacuum process. The specimens treated with vacuum process $\mathrm{C}$ had no fungal colony growth, including no Aspergillus niger, Penicillum sp., or Trichoderma viride, was produced. Unfortunately, Mucor sp. produced about 20 to $30 \%$ of fungal growth after being inoculated for over 30 days. When treated with vacuum process $\mathrm{A}$ or $\mathrm{B}$, the specimens, after having been inoculated with various types of fungi did not obtain an acceptable result. The fungal colony growth for Aspergillus niger and Mucor sp. was over $80 \%$ after being inoculated for 20 days, for Trichoderma viride it was about $70 \%$, and for Penicillum sp. It was about $25 \%$. These results indicate that the fungi resistance of various molds is related to the amount of absorption of bamboo vinegar, as shown in (Table 1). As a result of longer periods of vacuum and impregnation, the higher the uptake of bamboo vinegar, the better the fungi resistance on the surface of the steamed Moso bamboo.

The results of the fungal resistance of the car- 


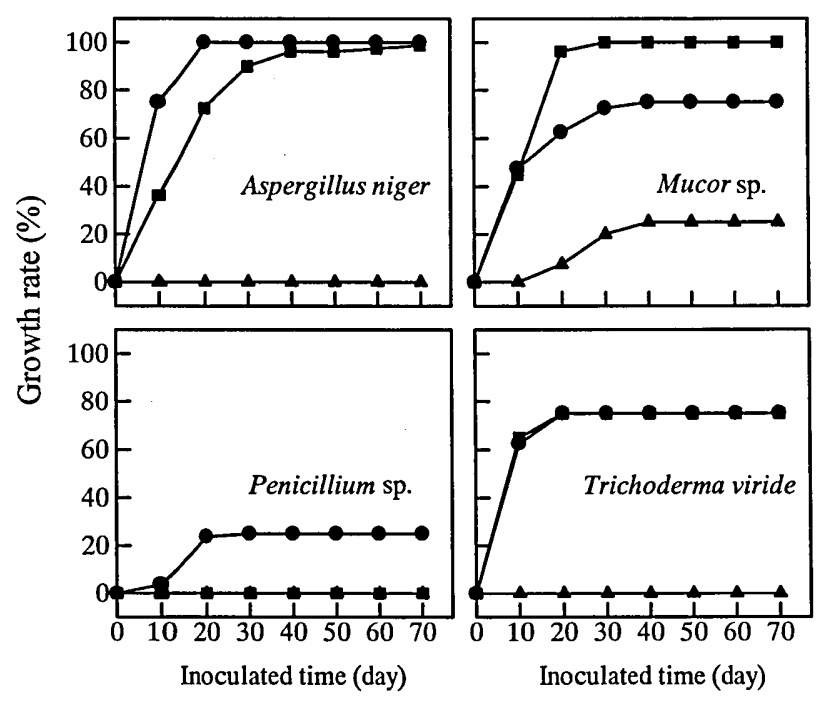

Fig. 1. Growth rate of various fungi inoculated on steamed specimens with various processes.

Symbols: $\rightarrow: \mathrm{A}, \rightarrow-\mathrm{B}, \rightarrow \mathrm{C}$.

Note: Abbrevations of A, B and C are the same as Table 1.

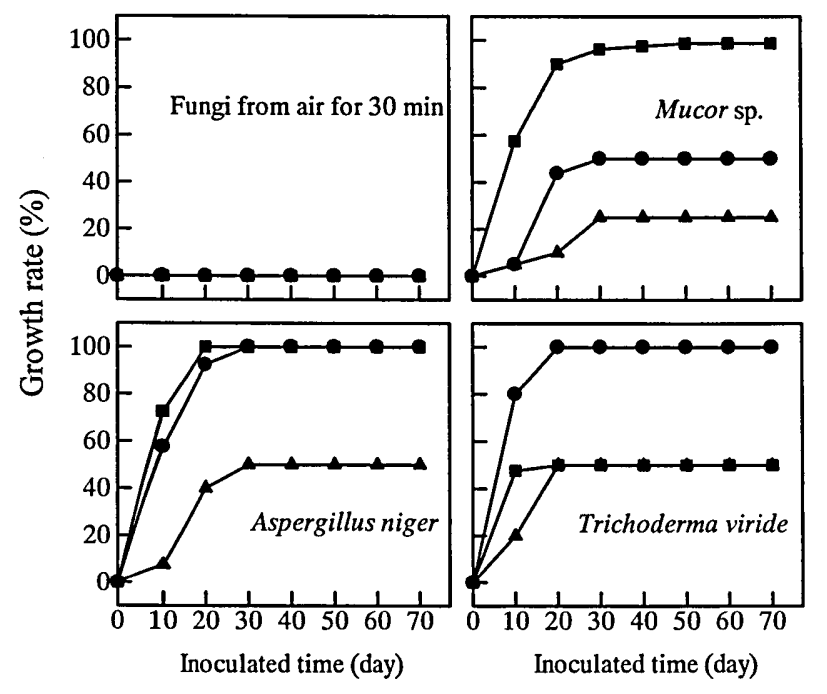

Fig. 2. Growth rate of various fungi inoculated on carbonized Specimens with various processes.

Symbols: - $-: \mathrm{A}, \boldsymbol{\rightarrow}-\mathrm{B}, \boldsymbol{\mathrm { B }} \rightarrow \mathrm{C}$.

Note: Abbrevations of $\mathrm{A}, \mathrm{B}$ and $\mathrm{C}$ are the same as Table 1.

bonized bamboo specimens are shown in Fig. 2. As expected, the resistance to fungi for the specimens treated with the vacuum process A and B was ineffective. After Aspergillus niger, Mucor sp., or Trichoderma viride had been inoculated on WA at $25^{\circ} \mathrm{C}$ in an incubator for 20 days, it showed $100 \%$ fungal growth for Aspergillus niger, about 40 to $80+\%$ for Mucor sp. and Trichoderma viride. However, when the specimens were exposed to fungi from the air for 30 $\mathrm{min}$, an excellent fungal resistance was obtained for the specimens treated by vacuum process $\mathrm{A}$ and $\mathrm{B}$, as they showed no fungal colonies at all (left top of Fig. 2). The fungal resistance of the carbonized specimens, after being treated with the vacuum process $\mathrm{C}$ was effective for restraining the molds, as the fungal growth of Aspergillus niger was only about $40 \%$ after being inoculated for 20 days, about $35 \%$ for Trichoderma viride, and $10 \%$ for Mucor sp. It can therefore be said that the carbonized specimens, when compared to the steamed ones (Fig. 1), are easier to be damaged by mildew attack on the bamboo surface. Furthermore, when comparing the attack of various fungi from both specimens from various processes, it was found that Trichoderma viride and Mucor $\mathrm{sp}$. belong to a stronger mold when considering the microbiological deterioration of the bamboo materials. Shiah et al. (2002, 2004) reported that Trichoderma viride and Mucor sp., followed by Chaetomium globosum, Metarrhizium sp. and Aspergillus niger, were able to cause a critical microbiological deterioration on filter paper resulting in a weight loss of about 30 to $40 \%$, as well as a reduction in the degree of polymerization (DP).

As described above, bamboo vinegar can restrain the molds and decrease microbiological deterioration of bamboo materials. It is believed that the application of bamboo vinegar with a high level of absorption can be used to prevent mildew attack on the bamboo surfaces. Our study indicated that only some of the compounds in bamboo vinegar can prevent mildew attack on the bamboo surfaces. Therefore, it is extremely necessary for future research to investigate which of the organic compounds in Moso bamboo vinegar are the main fungicides.

\section{C/N ratio analysis}

Bamboo, one of the green renewable resources, is essentially composed of the elements $\mathrm{C}, \mathrm{H}, \mathrm{O}$, and some trace elements, such as $\mathrm{Na}, \mathrm{K}, \mathrm{Ca}$, and $\mathrm{N}$, etc. It is easily damaged by the attack of microbiological agents, especially by fungi, and this seriously affects the end-value of bamboo products. The nitrogen (N) content was therefore useful for evaluating the degree of damage done by microbiological deterioration, since the amount of amino acid by-product increased because of the metabolizing of the fungal microorganisms. In other words, a higher amount of element $\mathrm{N}$ could indicate the degree of microbiological deterioration (Rayner and Boddy, 1988; Fukuda, 2000; Lin, 2003). The degree of microbiological deterioration can be expressed by the $\mathrm{C} / \mathrm{N}$ ratio. This is because the $\mathrm{C} / \mathrm{N}$ ratio can be used as an index to essentially estimate the relationship between the change of elemental compositions and the degree of biodegradations (Fujida, 1993). It is generally said that the lower the $\mathrm{C} / \mathrm{N}$ ratio, the greater the rate of biodegradations.

Figure 3 shows that the $\mathrm{C} / \mathrm{N}$ ratios of the two types of specimens were related to the various processes, after the three types of fungi were inoculated on WA for 70 days. In comparison with both control specimens (without bamboo vinegar process), the $\mathrm{C} / \mathrm{N}$ ratios for both specimens treated with various vacuum processes increased with the increase in time of vacuum and impregnation, that is, the specimens after being treated with vacuum process $\mathrm{A}$ had a lower $\mathrm{C} / \mathrm{N}$ ratio, indicating that a higher fungal growth was being produced. On the 


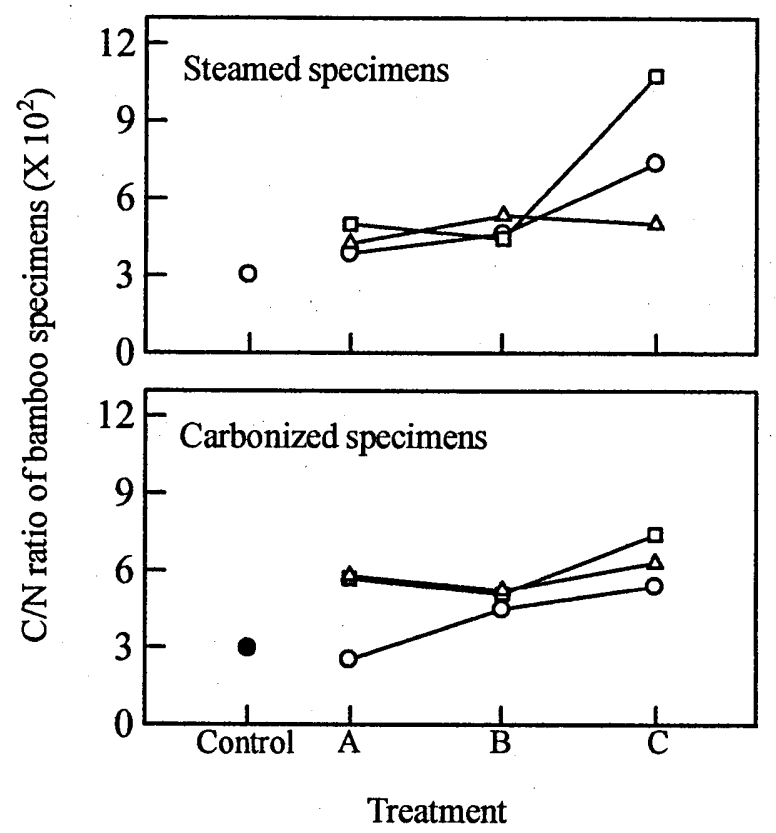

Fig. 3. $\mathrm{C} / \mathrm{N}$ ratio of various fungi inoculated on two types of specimens with various processes after 70 days.

Symbols: $\bigcirc$ or $\bullet$ : Control (without fungi inoculation),

$\rightarrow-$ : Aspergillus niger,

$\neg \square-$ : Trichoderma viride,

$\rightarrow-$ : Mucor sp..

Note: Abbrevations of A, B and C are the same as Table 1.

other hand, after having been processed with vacuum process $\mathrm{C}$, the $\mathrm{C} / \mathrm{N}$ ratio for three sorts of fungi on the carbonized specimens was less than that for the steamed ones (top of Fig. 3). These results were corresponded to the results of fungal colony growth in Figs. 1 and 2, and correspond to the results of absorption as shown in Table 1. This suggests that the growth of fungal colonies can be restrained by controlling the time processed to vacuum and impregnation. In addition, the carbonized bamboo materials were easier to grow mold than the steamed ones, because the $\mathrm{C} / \mathrm{N}$ ratio of the steamed specimens for each process was greater than that of the carbonized ones.

\section{FTIR analysis}

Chang (1990) reported that FTIR, possessing many unique advantages, is a powerful and potential technique for the analysis and characterization of micro-specimens of various wooden materials, polymers, and microbiological deterioration, especially for the chemical modifications of materials. To understand the fungal resistance for these two types of bamboo specimens, treated with vacuum processes $\mathrm{A}, \mathrm{B}$, and $\mathrm{C}$ with bamboo vinegar, and then fungi inoculated on WA at $25^{\circ} \mathrm{C}$ incubator for 70 days, the specimens were examined using FTIR analysis, and the results are shown in Fig. 4.

The FTIR spectra for Aspergillus niger inoculated on the steamed specimens with various processes (A, B, and $C$ ) after 70 days, and Aspergillus niger only (D) are shown in the top of Fig. 4. The results show that for vacuum processes $\mathrm{A}, \mathrm{B}$ and $\mathrm{D}$, two absorbance peaks located at $1654 \mathrm{~cm}^{-1}$ and $1552 \mathrm{~cm}^{-1}$, were assigned to $\mathrm{C}=$

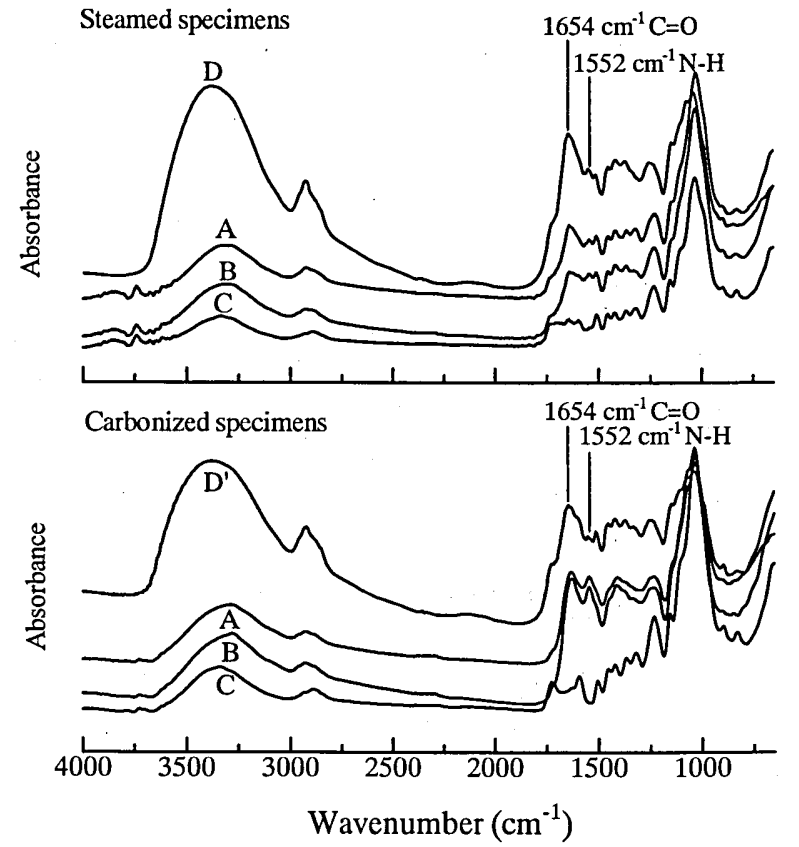

Fig. 4. FTIR spectra of fungi inoculated on two types of specimens with various processes after 70 days.

Symbols: D: Aspergillus niger only, D': Mucor sp. only.

Notes: Steamed specimens inoculated with Aspergillus niger, Carbonized specimens inoculated with Mucor sp., Abbrevations of A, B and C are the same as Table 1.

$\mathrm{O}$ (carbonyl group) stretching and $\mathrm{N}-\mathrm{H}$ deformation vibration, respectively. However, neither was found in the vacuum process $C(C)$. These results are the same as the results of the carbonized specimens inoculated with Mucor sp., with various processes after 70 days and Mucor sp. only (D'), as shown in the bottom of Fig. 4. It seems that both stronger absorbances are the representative function groups of the fungal chemical compounds, while the fungal colony growth is shown on the bamboo surface. This is because the main compounds for the cell wall of the fungi include chitin, cellulose, aminosaccharides, protein, etc. And as such $\mathrm{C}=\mathrm{O}$ can be a representative for their function group (Chang, 1990). For the function group N-H, it can be the products of amino acid that were increased through the metabolizing of fungal microorganisms (Shiah et al., 1999 and 2004). Therefore, it is concluded that bamboo vinegar is useful to restrain molds when the bamboos are treated with the vacuum process at $60 \mathrm{~min}$ of vacuum and 240 min of impregnation time. From the results of the $\mathrm{C} / \mathrm{N}$ ratio and the FTIR analysis it is evident that bamboo vinegar enables a decrease of microbiological deterioration in bamboo materials.

\section{ACKNOWLEDGEMENTS}

The authors are grateful to the Pu Yuan Co. Ltd., Nantour, Taiwan, for providing the experimental materials, bamboo vinegar and experimental specimens, two types of treated Moso bamboo materials. We offer our sincere appreciation to both the National Science Council through Grant No. NSC 93-2622-B-415-CC3, 
and the Huei Yuh Industry Co. Ltd., Taipei, Taiwan for financial support.

\section{REFERENCES}

Chang, T. T., Y. Lu, and D. Chen 1983 The Aerial Fungi Flora in Taipei. Psychopathologist \& Entomologist, NTU, 10: 1-15

Chang, S. T. 1990 Chemical Characterization of Woody Materials and Coatings Using Fourier Transform Infrared Microspectroscopy. Quarterly Journal of Chinese Forestry, 23 (1): 87-103.

Council for Cultural Affairs 2002 Manual for Collections Care. Cultural Council Affairs Publication, pp. 88-89

Fujida, K. 1993 Composite Technology. Gihoutou Publication, pp. $69-70$

Fukuda, K. 2000 Deterioration and Increasing Durability of Thatched Roof. Data of Wood Research, 16: 1-16.

Ikimoto, T., O. Ikeshima. 2000 Usages of Bamboo Charcoal and Bamboo Vinegar. Nobunkyou Publication, pp. 89-107

Kobahasi, Y. 2004 Reductive Effectives of Agricultural Chemical. Nobunkyou Publication, pp. 146-149.

Liese, W. 1980 Preservation of Bamboo. Bamboo Research in Asia. IDRC, Canada, pp. 165-172.

Lin, F. C. 1995 Agricultural Usage of Bamboo Charcoal and Bamboo Vinegar. TanYi Publication, pp. 28-30.

Lin, J. C. 2003 Investigation and Analysis on Weather Degradation of Wood Construction Materials for Traditional Taiwanese Architectures. Ph. D Dissertation, pp. 144-157

Mizuki, B. 2004 Decrease of Agricultural Chemical to Apple Tree. Nobunkyou Publication, pp. 86-88

Nomura, R. 2004. Healthy Effects of Bamboo Vinegar. Nobunkyou Publication, pp. 141-143.

Okano, K., M. Suzuki, M. Haishi, K. Zonomoto, N. Zouta, T. Takahashi, H. Nitakai, I. Minadokuchi, and T. Akiyama. 1995 Wooden Residence Environment - Handbook -. Asakusa Publication, Japan, pp. 114-122
Rayner, A. D. M., L. Boddy. 1988 Fungal decomposition of Wood-Its Biology and Ecology. A Wiley-Interscience Publication, Chichester, New York, Brisbane, Toronto, Singapore, pp. 38-46.

Shieh, B. T. 1976 Preservation, Insect and Fungi Resistance of Bamboo Materials. J. of TFRI, 10 (2): 1-14.

Shiah, T. C., F. J. Chang. 2002 Separation and Identification of Foxed Spots on Paper-based Cultural Relics. Forest Products Industries, 24 (4): 29-44.

Shiah T. C., H. L. Lee, T. T. Chang, M. H. Duh, and C. C. Chen. 2004 Application of Gamma Radation to the Disinfection of Mold on Wood. Forest Products Industries, 23 (3): 249-262.

Sulthoni, A. 1988 Traditional Preservation of Bamboo in Java Indonesia. In "Proceedings of the Third International Bamboo Workshop", Cochin, India, pp. 349-357

Takeuchi, T. 2000 Porous Materials - Characterization, Production and Application-. Fuji TecoSystem Publication, pp. $137-144$

TAPPI 1993 Fungus Resistance of Paper and Paperboard. Microbiology and Microbial Technology Committee of Research and Development Division, pp. 1-4

The annual Statistics of the Agricultural Reports. 2003 Forestry Bureau, Council of Agriculture, Executive Yuan, ROC. Forestry Bureau, Council of Agriculture, Executive Yuan Publication.

Hageta, Y. 2004 Application of Wood/Bamboo Vinegar on the Cultivation of Grape. Nobunkyou Publication, pp. 84-85

Uchimura, T., H. Tanikai, and K. Hosoukawa 2000 Issues of Bamboo Charcoal and Bamboo Vinegar. Soumorisya Publication, pp. 138-168

Wang, D., S. J. Shen. 1987a Bamboo of China. Time Press, Portland, Oregon, p. 167

Wang, S. Y., S. J. Lin, M. J. Tsai, and S. C. Wu. 1987b Studies on the effects of Mold-Retarding on Sanitary Bamboo Chopsticks Treatment. Forest Products Industries, 6 (3): 1-10

Yoshie, L. 2004 Effects of Wood/Bamboo Vinegar on Cow Skin. Nobunkyou Publication, pp. 132-133 